\title{
Integração de Saberes na Educação do Campo: Proposições teórico-metodológicas
}

\author{
Integration of Knowledge in Rural Education: Theoretical-methodological \\ proposals \\ Felipe Junior Mauricio Pomuchenq
}

Resumo: Com o objetivo de apresentar aprofundamentos teóricos e metodológicos sobre a integração dos saberes, em especial na educação do campo; e refletir sobre a importância da visão ampla do conhecimento para a aprendizagem do estudante, o presente trabalho busca trazer orientações para a integração de saberes no ensino na educação do campo. Utilizou-se da Revisão de Literatura, a partir de artigos apresentados no Encontro Nacional de Didática e Práticas de Ensino (ENDIPE) entre 2012 e 2016 e nas produções do Programa de Pós-Graduação em Ensino na Educação Básica (CEUNES/UFES). Verificou-se que a integração dos saberes pode se concretizar de diversas formas, tais como projetos, interdisciplinaridade, estudo da realidade, mas sempre prezando pelo respeito aos diversos saberes que a humanidade produz. Aspectos como a articulação entre desenvolvimento científico e capitalismo, formação fragmentada dos professores, práticas individualistas, estrutura "fechada" dos currículos, e a sobreposição da ciência, vem se mostrando um desafio na superação de uma visão reducionista do conhecimento.

Palavras-chave: Integração de Saberes. Educação do Campo. Conhecimento.

Abstract: In order to, Present theoretical and methodological insights on the integration of knowledge, especially in rural education; and Reflect on the importance of a broad view of knowledge for student learning, this paper seeks to provide guidelines for the integration of knowledge in teaching in rural education. We used the Literature Review, from articles presented at the National Meeting of Didactics and Teaching Practices (ENDIPE) between 2012 and 2016 and in the productions of the Graduate Program in Teaching in Basic Education (CEUNES / UFES). It was found that the integration of knowledge can take place in different ways, such as projects, interdisciplinarity, reality study, but always respecting the different knowledge that humanity produces. Aspects such as the articulation between scientific development and capitalism, fragmented teacher training, individualistic practices, "closed" curriculum structure, and the overlap of science, have been proving to be a challenge in overcoming a reductionist vision of knowledge.

Keywords: Integration of Knowledge. Rural Education. Knowledge.

\section{Introdução}

Somos sujeitos históricos, modificamos e somos modificados pelo meio que estamos inseridos, ou seja, nossa realidade, que é formada pelos conhecimentos tradicionais e científicos, pelas pessoas que ali vivem, pela cultura que se constrói e se reconstrói à medida que os diferentes sujeitos atuam e transformam o meio. Neste sentido, devemos compreender que tanto a 
realidade como os sujeitos que nela estão inseridos, que também se tornam a realidade, não é estática, mas carregada de características que se manifestam. Portanto, a realidade é ampla, e todas suas partes dialogam, e no caso da educação, quando o estudante chega à escola, traz consigo todas estas características, afinal, o processo de formação não só acontece na escola, apenas continua (GALLO, 2008).

No contexto da educação do campo, percebemos um território fértil para o desenvolvimento desta temática. Através da valorização dos saberes que os camponeses carregam ao longo da história, e posteriormente, fazendo os possíveis e fundamentais elos com os conhecimentos técnico e científicos que a humanidade produz, propicia-se a formação ampla dos educandos, sem desvinculá-los da realidade, ao contrário, promovendo o sentimento de pertença pelo campo com um espaço de luta, resistência e produção de conhecimentos.

A partir desta produção, fruto de uma pesquisa de mestrado, objetiva-se apresentar aprofundamentos teóricos e metodológicos sobre a integração dos saberes, em especial na educação do campo; e refletir sobre a importância da visão ampla do conhecimento para a aprendizagem do estudante. Para alcançar estes objetivos, utilizou-se da revisão de literatura como instrumento metodológico, sendo analisado as seguintes fontes: As dissertações do programa de pós-graduação em ensino na educação básica (CEUNES/UFES), onde identificamos seis trabalhos que se articulavam com esta temática, e dos artigos apresentados no Encontro Nacional de Didática e Práticas de Ensino (ENDIPE) dos anos de 2012, 2014 e 2016, em que encontramos um total de dez trabalhos.

\section{Integração de Saberes e a Formação do Educador}

Sem pretender adotar uma ideologia salvacionista para a escola ou para as práticas de ensino levadas a cabo por profissionais professores, acreditamos veementemente possível se repensar a práxis pedagógicas por outra ótica que busque a religação entre os saberes que constituem os componentes curriculares (D'ÁVILA, 2012, p.393). 
Cunha (2014) destaca que o ensino é uma ação complexa, pois envolve diferentes sujeitos, de contextos diversos que se "confrontam" durante os processos de ensino e aprendizagem, desta forma, eis um dos primeiros motivos que fundamentam a necessidade de o professor possuir saberes que vão além dos disciplinares, mas também, saberes da didática do ensino.

No contexto da educação, podemos refletir que uma função do professor é de dispor de conhecimentos científicos que o estudante ainda não possui, e assim, ir construindo novos saberes a partir da relação com os estudantes, em diálogo com a realidade onde está inserido. Portanto, integrar saberes requer reconhecer que o conhecimento não se produz de forma isolada, sendo preciso pôr os diferentes saberes em diálogo, e assim novos saberes serão produzidos, num processo de dialeticidade,

Por isso, um só saber não dará conta da tarefa de ensinar. Como o ensino ocorre em diferentes situações, não se pode utilizar um saber de forma isolada (no caso, o saber disciplinar, dos conteúdos), mas sim um conjunto de saberes de forma articulada para dar conta do processo (CUNHA, 2014, p.68).

Carvalho (2012), em sua produção intitulada "Entre Caminhos e Conhecimentos Pedagógicos: caminhos possíveis ao desejável diálogo de saberes", aborda sobre a importância da integração de diferentes saberes na formação dos professores, e destaca que este processo ocorre desde a universidade (formação inicial) se estendendo após a saída desta etapa, quando se inicia a formação continuada.

Para a integração de saberes, Carvalho (2012), realça que, o fato de integrar o conhecimento científico com saberes ligados à vivência do próprio educador, proporciona melhor aprendizagem sobre o conteúdo a ser estudado, contribuindo com uma formação que extrapole a disciplinaridade, tornando o conhecimento significativo o conhecimento apreendido,

A ciência como prática cultural e social passa a ser vista, assim, como um componente curricular que pode contribuir para a construção da identidade de nossos alunos como indivíduos cidadãos, participantes ativos em possíveis processos de construção de uma sociedade democrática e socialmente justa (CARVALHO, 2012, p.358). 
Segundo Carvalho (2012), a realização de práticas de ensino caracterizadas pela integração de saberes, requer por parte do educador uma postura dialógica, reconhecendo o outro, a outra área, o outro conhecimento, sendo este processo, um desafio, pois na atualidade, por influência do positivismo, a sociedade menospreza os conhecimentos das ciências humanas, pondo em sobreposição os conhecimentos das ciências da natureza,

A concepção epistemológica dominante, historicamente construída ao longo dos últimos três séculos, própria da ciência moderna e, em muito, influenciada por matrizes epistemológicas vinculadas ao Positivismo, atribui às Ciências Exatas e da Natureza a condição por excelência de conhecimentos científicos e socialmente legitimados (CARVALHO, 2012, p. 362).

D’Ávila (2012), aborda a importância do trabalho integrado visando à compreensão da totalidade pelo estudante. A autora salienta que, a realidade é interligada, mas a formação do educador é fragmentada e disciplinar, e desta forma, surge um grande desafio para o educador atuar de forma diferente de sua formação, pois "Há uma tendência em se reproduzir o modelo de ensino que vivenciaram na formação inicial” (D’ÁVILA, 2012, p.386).

A interdisciplinaridade, segundo D'Ávila (2012), se apresenta então como uma alternativa na prática docente, como forma de trabalhar e compreender 0 conteúdo nas relações que o mesmo estabelece com outros saberes, e que muitas vezes são ignorados pela escola, "Assim a interdisciplinaridade [...] é um modo de compreender o processo de conhecimento, bem como trabalhar de modo integrado os conhecimentos interdisciplinares" (D’ÁVILA, 2012, p.387). Para a realização da interdisciplinaridade, a atuação das disciplinas é fundamental, ou seja, não se realiza interdisciplinaridade eliminando disciplinas, mas colocando seus conhecimentos em relação e diálogo.

Do ponto de vista da ciência, disciplina é um tipo de saber específico e possui um objeto determinado e reconhecido, bem como conhecimentos e saberes relativos a este objeto e métodos próprios. [...] A tentativa de estabelecer relações entre as disciplinas é que dá origem ao que chamamos interdisciplinaridade ${ }^{1}$ (D’ÁVLIA, 2012, p.387).

\footnotetext{
${ }^{1}$ Grifo da autora.
} 
Entretanto, na realização da interdisciplinaridade alguns desafios se apresentam, sendo eles, a própria formação disciplinar do educador; a imposição dos conhecimentos dos livros didáticos; a resistência dos professores em sair de seu espaço disciplinar e realizar planejamento coletivo; e as condições que as escolas oferecem, que na maioria das vezes não enxergam outras possibilidades de compreensão dos saberes. Portanto, além de mudar a prática, é fundamental que aos poucos se mude a estrutura de escola que se concretiza na realidade, como destaca D’Ávila (2012, p.393), "Para se mudar a escola, e sua lógica baseada na visão dualista da verdade, vamos precisar mudar nosso olhar em busca de práticas curriculares integradoras".

Adentrando na especificidade de nossa pesquisa, que é o contexto da educação do campo, analisamos ainda a produção de Sperandio (2016), na qual a autora traz uma reflexão sobre a formação dos professores frente às diversidades educacionais no contexto da educação do campo. Após um breve histórico da criação de escolas localizadas no campo no estado do Espírito Santo, a autora destaca que a chegada destas instituições possuía como intenção, suprir as carências de matrículas do campo, e também de profissionalizar os jovens para atuar neste ambiente (SPERANDIO, 2016). Com a chegada da Pedagogia da Alternância, através das Escolas Famílias Agrícolas (EFA's), constrói-se uma perspectiva de formação ampla dos sujeitos que estão inseridos no campo, através da defesa deste espaço de vida para a população rural camponesa, ambiente este que também produz conhecimentos.

Ao contextualizar a diversidade educacional no campo, identificamos experiências escolares que articulam a ação educacional e a formação de professores a saberes, identidades, modos de produção de vida e trabalho do campo (SPERANDIO, 2016, p.10872).

Ainda neste contexto da Formação dos professores na Educação do Campo, Melzer (2016), em seu trabalho, "Diálogo de Saberes na Licenciatura em Educação do Campo da UFPR Litoral", contextualiza inicialmente a Licenciatura, e descreve as práticas pedagógicas utilizadas pelo curso, que possibilitam o diálogo de saberes na Educação Superior. O trabalho realiza uma caracterização do Projeto Pedagógico do Curso, destacando que, ao indicar a 
utilização de projetos como prática pedagógica, possibilita a construção de saberes pelo estudante, garantindo a integração de conhecimentos científicos e populares.

Dessa forma, pode-se depreender que o projeto de educação popular que o curso se propõe a desenvolver está intimamente ligado com fundamentos do diálogo de saberes pressupondo uma relação de cooperação entre os saberes das comunidades, saberes da experiência individuais do educando e educador e saberes acadêmico-científicos, gerando uma relação descolonizadora, ou seja, uma relação de construção de uma nova compreensão de conhecimento, gerado nas relações dialógicas de cooperação entre educador (que media) e educando (mediado) (MELZER, 2016, p.10829).

Esta proposta de integração de saberes, pressupõe um novo currículo para a escola, que observa as diversidades que envolvem a mesma, que utilize de situações problemas da realidade, um currículo em que os educadores se disponham a atuar rompendo o individualismo de suas disciplinas, o que muitas vezes é um desafio, pois a formação dos educadores é baseada numa especialização do conhecimento, como destacado pela autora,

O desafio para o estabelecimento de um efetivo diálogo entre saberes parte da experiência individual de cada docente e de sua formação, partindo do pressuposto que as caminhadas teóricas dos docentes são diferenciadas, o que confere uma diversidade de orientações teóricas e, por enquanto, certa dificuldade em produzir encaminhamentos conjuntos dentro de uma unidade teórica (MELZER, 2016, p.10833).

Os trabalhos de Melzer (2016) e Sperandio (2016), trazem importantes aspectos sobre a Integração de Saberes na Formação dos Professores na educação do campo, sendo um dos principais a necessidade de ampliar as visões e práticas de currículo na escola, rompendo as grades que os mesmos possuem, que impedem o diálogo entre os diferentes conhecimentos e disciplinas. Os trabalhos sinalizam possíveis práticas, em destaque a produção de Melzer (2016), que traz a especificidade da Licenciatura em Educação do Campo, pois ao proporcionar uma formação do educador por área do conhecimento, que estabelece um diálogo com a realidade onde o estudante está inserido, proporciona a integração de diferentes saberes, ampliando a compreensão da realidade e do conhecimento. 


\section{Integração de Saberes e Práticas Curriculares}

O Conhecimento possui fronteiras que se deslocam (Almeida et al., 2012, p.1718).

Almeida; Silva \& Syrgiannis (2012), em sua produção intitulada "Interdisciplinaridade: um caminho didático para a criatividade e inovação", abordam os principais conceitos de interdisciplinaridade, destacando de início que esta prática possibilita em si um diálogo entre os diferentes conhecimentos no âmbito da escola. Os conceitos de interdisciplinaridade que as autoras trazem, estão relacionados com as pesquisas de Fazenda e de Japiassú. Segundo as autoras, em Fazenda (2005), a Interdisciplinaridade exige uma nova postura por parte do educador, esta prática requer "investigação" e "abertura à compreensão de aspectos ocultos do ato de aprender e de um novo olhar sobre as ciências" (ALMEIDA; SILVA \& SYRGIANNIS, 2012, p.1721). Para Japiassu (1991), a "interdisciplinaridade procura descobrir e/ou estabelecer conexões e correspondências entre as disciplinas científicas" (ALMEIDA; SILVA \& SYRGIANNIS, 2012, p.1719), reforçando que, interdisciplinaridade não é eliminar disciplinas, mas pôr os seus conhecimentos em diálogo.

Na produção de Ivani Fazenda (2014), a autora aborda uma reflexão sobre o conceito de interdisciplinaridade, que está além de juntar disciplinas, mas "como atitude de ousadia e busca frente ao conhecimento" (FAZENDA, 2014, p.933), desta forma, esta prática nos impulsiona a rever o ato de ensinar, na busca da constante construção e reconstrução dos saberes. A interdisciplinaridade assume então a ideia de que diferentes saberes devem estar em diálogo, buscando estabelecer relações entre conhecimento científico e conhecimento do senso comum, entre teoria e prática, por isso, cada disciplina assume papel importante e fundamental neste processo,

Por isso, entendemos o seguinte: cada disciplina precisa ser analisada não apenas no lugar que ocupa ou ocuparia na grade, mas, nos saberes que contemplam, nos conceitos enunciados e no movimento que esses saberes engendram, próprios de lócus de cientificidade (FAZENDA, 2014, p.934).

Os trabalhos de Almeida; Silva \& Syrgiannis (2012) e Fazenda (2014), discutem a temática da interdisciplinaridade, sendo que estas diferentes 
produções direcionam que, a interdisciplinaridade pode ser uma possibilidade de diálogo de sabres no contexto da escola, mas ao mesmo tempo se alinha a estrutura disciplinar dos currículos. Para esta pesquisa, buscamos lançar olhares para além das disciplinas e do conhecimento científico, pois ao observar e trazer para o contexto da escola, o conhecimento popular e a cultura no qual o estudante está imerso, propiciamos um encontro e uma integração entre o sujeito consigo mesmo, contribuindo para que a ciência seja compreendida sem a necessidade de uma ruptura com a realidade.

Serafim \& Maia (2014), abordam a temática da utilização de projetos como prática pedagógica que possibilita a interdisciplinaridade na escola. Os projetos são iniciativas que possibilitam romper o isolamento das disciplinas, articulando teoria e prática, e como destaca as autoras, tornando professores e estudantes parceiros no processo formativo. Segundo as autoras, integrar disciplinas possui como justificativas,

[...] a necessidade de o saber preparar para a vida, o desenvolvimento de conteúdos a partir da valorização dos níveis de desenvolvimento/conhecimento dos alunos e, por fim, a participação mais direta dos alunos, por meio da sugestão dos temas no processo de ensino-aprendizagem (SERFAIM \& MAIA, 2014, p.3948).

Segundo Serafim \& Maia (2014), a utilização de projetos propicia melhores índices de aprendizagem por parte dos estudantes, e ainda uma nova visão de currículo e de prática docente por parte do educador,

Certos de que teoria e prática caminham melhor quando o ensino é pautado em conexões de conhecimentos e informações, acreditamos que o professor ao trabalhar em uma perspectiva interdisciplinar lança um novo olhar para o currículo escolar, e consequentemente, para seu fazer pedagógico, vendo o aprendiz como um grande parceiro em sua prática docente (SERAFIM \& MAIA, 2014, p.3955).

O fato de os projetos contribuírem para romper com o isolamento das disciplinas é um grande avanço, porém, é preciso construir estratégias que garantam relações entre os projetos, e pensar os mesmos na articulação com os saberes que estão imersos na realidade da escola pelo estudante. 
A partir de uma pesquisa sobre as escolas multisseriadas, Gerke (2016) salienta que, a metodologia de ensino nestas escolas contribui para que diferentes saberes dialoguem no ambiente educacional. A autora afirma que as escolas multisseriadas proporcionam maior participação das famílias no ensino, afinal elas estão próximas da unidade de ensino, podendo acompanhar seus filhos, além de dialogar muito com os educadores. Mesmo diante destas potencialidades, a produção de Gerke (2016), aponta que é preciso repensar o currículo da escola do campo, numa perspectiva de ajustar um diálogo entre os diferentes saberes que estão imersos na escola, "Nesse sentido, pensar no currículo do campo é pensar na vida campesina" (GERKE, 2016, p.10895), e trazer para dentro do espaço escolar o território em que a mesma está inserida, sendo necessário que o educador repense constantemente suas práticas de ensino, como destaca a autora, "O que se busca é uma prática de ensino que tem como eixo a cultura e o trabalho do campo como possibilidades de permanência digna dos povos do campo em seus territórios" (GERKE, 2016, p.10895).

Veloso (2016), em sua produção sobre currículo e didática, apresenta que os diferentes saberes estão conectados, e ampla é a função do educador no fato de, possibilitar que o estudante compreenda o conhecimento de forma articulada com os saberes que ele possui ao adentar na escola. A autora salienta que, o currículo escolar, ao descrever os conteúdos que serão trabalhados, leva em conta os saberes que uma classe dominante acredita ser necessário para que as demais classes aprendam, ou seja, na prática, são diferentes currículos, com diferentes saberes que se efetivam nas escolas, rompendo com uma ideia de neutralidade do currículo escolar,

Portanto, os interesses que serviram como base para a atuação dos mais influentes especialistas em currículo não foram e não são neutros. Eles assumem compromissos com estruturas e políticas educacionais específicas, que contribuíram e ainda hoje contribuem para a promoção de desigualdades sociais (VELOSO, 2016, p.6353).

Desta forma, como destaca Veloso (2016, p.6354), "aqueles que se mostram mais necessitados de educação sejam aqueles que menos recebem educação", ou seja, as classes sociais menos favorecidas, não tem acesso ao 
conhecimento científico em sua profundidade. Outro aspecto apresentado pela autora, é que os saberes que são trabalhados na escola não dialogam entre si, são conhecimentos segregados, sem conexão, o que impossibilita a compreensão por parte do estudante pelo conhecimento em sua forma ampla, superar estas barreiras é compreender que,

Educar precisa ser compreendido como ato mais complexo que a ordenação de métodos e técnicas de ensino, cercadas pela elaboração de eficientes objetivos educacionais e eficazes procedimentos de ensino. É ato político que envolve poder por espaços privilegiados de conhecimento e que, nesse campo, currículo e didática são fundamentais instrumentos de luta por uma educação mais equânime do ponto de vista social e mais problematizadora do ponto de vista metodológico (VELOSO, 2016, p.6356).

\section{Integração de Saberes e Educação do Campo}

Do meio brota a indagação, a inquietação e problematização. A escola é o local de escuta e reflexão dos problemas levantados, ou seja, receptora das inquietações e propulsora da ação reflexiva (OLIVEIRA, S. 2016, p.56).

Oliveira, E. (2016), em sua produção "A interdisciplinaridade na perspectiva de integrar as disciplinas da área de ciências da natureza e matemática" apresenta os principais conceitos, objetivos e abordagens de interdisciplinaridade, trazendo reflexões sobre as contribuições desta prática e teoria para o currículo da escola. Inicialmente, destacamos que a formação disciplinar nas escolas acontece ao longo da história, alinhada a expansão do capitalismo, se intensificando numa formação para o mercado de trabalho, através das especializações do conhecimento. As disciplinas, segundo Oliveira, E. (2016), possuem importância como lócus de organização do conhecimento, porém, este processo de fragmentação, interfere na compreensão da totalidade pelo estudante, e distanciou a teoria da prática, e como consequência, se produziu uma formação desconectada da realidade,

A fragmentação do conhecimento científico, no âmbito educacional, manifesta-se na separação das disciplinas no 
currículo escolar, na qual, muitas vezes, até mesmo dentro da mesma área de conhecimento são apresentados de maneira desvinculada e desconexa [...] (OLIVEIRA, E. 2016, p.29).

Mesmo diante desse movimento de especialização, a realidade vai impondo a necessidade do retorno de uma visão ampla do conhecimento estudado. Desta forma, a interdisciplinaridade se apresenta como uma possibilidade para esta ótica,

Já a Interdisciplinaridade, compreende o nível de associação entre disciplinas, supõe o diálogo e uma troca de conhecimentos, em que a cooperação entre várias disciplinas provoca intercâmbios reais; isto é, existe verdadeira reciprocidade nos intercâmbios e, consequentemente, enriquecimentos mútuos (OLIVEIRA, E. 2016, p.65).

Ao refletir sobre os conhecimentos que estão fora do âmbito disciplinar, Lima (2017) afirma que a formação do estudante vai além de estudar apenas os conhecimentos disciplinares, sendo preciso abordar demais saberes que envolvem a realidade do estudante, rompendo as hierarquias de conhecimentos que a ciência moderna impõe, na qual o científico e disciplinar se torna superior aos demais saberes que a sociedade vem ao longo da história produzindo,

Nessa perspectiva, a fragmentação dos saberes, a partir da ciência moderna, proporcionou o surgimento cada vez maior da necessidade de especializações, que se configuram em blocos engessados, ricos em profundidade nos aspectos particulares, porém limitados na visão do todo (LIMA, 2017, p.58).

Para Lima (2017), o conhecimento científico, além de se estruturar como único e verdadeiro, não se encontra disseminado de forma igualitária na sociedade, fortalecendo uma estrutura de desigualdade sócia de acesso ao conhecimento. Neste sentido, o autor afirma que, é preciso enxergar e compreender os diversos saberes com base na perspectiva da Ecologia de Saberes, de Boaventura de Sousa Santos, pois todos saberes são importantes e fazem parte da formação humana,

A ecologia dos saberes e a interdisciplinaridade podem se configurar, num contexto de privação do saber à maioria, caminhos possíveis de luta contra a injustiça cognitiva e, por consequência, do abismo social que separa os que sabem e têm, dos que não sabem e nada têm. No entanto, é bom que se esclareça que não se trata apenas de distribuir o conhecimento 
a todos, mas de articulá-los e de aplicá-los à realidade, observando o contexto em que os sujeitos se inserem (LIMA, 2017, p.65).

Oliveira, E. (2016) e Lima (2017), reforçam as perspectivas desta pesquisa no que tange a um olhar integral que supere a fragmentação do conhecimento. Os autores abordam a necessidade do diálogo dos diversos conhecimentos, e Lima traz em específico os aprofundamentos sobre a Ecologia de Saberes de Santos (2010), em que cada saber ocupa um determinado espaço na compreensão da totalidade, superando as visões hegemônicas do conhecimento científico como único e verdadeiro.

Sobre a educação do campo, Lírio (2016), reforça que ao longo da história, a mesma ficou à margem das políticas públicas brasileiras, desde sua presença na legislação até a sua efetivação. Com isso, o campo se tornou um espaço em que estas políticas não se faziam presentes, proporcionando altos índices de analfabetismo, e a posterior inserção de um currículo centrado nas orientações urbanas. Entretanto, o movimento da educação do campo veio conquistando seus espaços, contribuindo para o fortalecimento de um projeto de educação contra-hegemônico, que se baseia na presença dos movimentos sociais do campo como protagonistas, na construção de uma educação vinculada a sua realidade,

A educação do campo, enquanto uma demanda social específica, nasceu de uma ação objetiva vinculada à necessidade de assegurar o direito à educação aos filhos dos trabalhadores, sendo que essa educação deveria ser adequada à realidade cultural e social específica desses sujeitos que atuam no campo (LÍRIO, 2016, p.53).

As escolas do campo segundo Lírio (2016), atuam na resistência, contrapondo o modelo de educação hegemônico e a expansão do agronegócio ${ }^{2}$ no campo,

\footnotetext{
2 Leite \& Medeiros (2012, p.79), assim definem agronegócio, "O termo foi criado para expressar as relações econômicas (mercantis, financeiras e tecnológicas) entre o setor agropecuário e aqueles situados na esfera industrial (tanto de produtos destinados à agricultura quando de processamento daqueles com origem no setor), comercial de serviços. Para os introdutores do termo, tratava-se de criar uma proposta de análise sistêmica que superasse os limites da abordagem setorial predominante". Ou seja, um projeto para o desenvolvimento do campo que por sua vez explora os recursos naturais, baseado na monocultura, no latifúndio, com o uso de
} 
Nessa perspectiva, compreendemos que as escolas do campo, também produzem elementos de resistência frente às concepções hegemônicas, cooperando, dessa forma, para que o espaço escolar não permaneça apenas como um ambiente que abriga sujeitos passivos, obedientes e desinteressados de suas realidades, mas sim sujeitos transformadores da realidade (LÍRIO, 2016, p.65).

Em sua contextualização sobre a educação do campo, Barbosa (2018) vai construindo um conceito de educação do campo calcado nas relações desta proposta de ensino com a realidade sócio histórica, ou seja, o movimento da educação do campo se constitui atrelado às lutas que os camponeses, em busca de uma educação de qualidade, travam no espaço do campo. A autora destaca os movimentos do I Encontro Nacional de Educadores da Reforma Agrária (ENERA) em 1997, e a I Conferência Nacional por uma Educação do Campo em 1998, como processos fundamentais na construção da educação do campo, e posteriormente na conquista de leis que amparassem este projeto.

A autora salienta ainda que a educação do campo busca se constituir como uma proposta de ensino que vai de encontro com a realidade dos camponeses, sendo necessário um currículo que estabeleça este diálogo,

Assim, é possível compreender a $\mathrm{EdC}^{3}$ como um projeto de educação dos e não para os camponeses, feita, por meio de Políticas Públicas, mas erguida em conjunto com as pessoas de direito que as exigem, identificada pelos sujeitos que a compõe. Se faz necessário compreender que, por trás de demarcações geográficas e informações estatísticas, existe um povo que luta, vive e constrói relações no campo, das mais diversas formas de identidades existentes (BARBOSA, 2018, p.44).

Nas perspectivas apontadas por Barbosa (2018), a educação do campo se constitui como um projeto de educação em rupturas, objetivando a formação ampla e integral dos sujeitos envolvidos, para que assim possam intervir na sua realidade,

A proposta da EdC é romper com a educação tradicional, portanto, o currículo nas escolas do campo tem como referência principal a formação integral e o modo de produção e reprodução da vida das comunidades camponesas. Para tanto, se assume

agroquímicos e destruição dos bens da natureza, e da divisão de classes no campo através de relações desiguais de trabalho.

${ }^{3}$ Educação do Campo. 
uma concepção de currículo integrado, objetivando uma integração entre os conhecimentos historicamente acumulados, conhecimentos sistematizados e os conhecimentos populares (BARBOSA, 2018, p.49).

Oliveira, S. (2016) faz um aprofundamento sobre o ensino de filosofia e a proposta da Pedagogia da Alternância (PA), enfatizando sobre os instrumentos pedagógicos que uma Escola Família Agrícola utiliza. Sobre a PA, o autor afirma que a mesma é uma proposta que busca estabelecer no ensino, vínculos entre o conhecimento científico e a vida do estudante, sendo ainda, segundo o mesmo, a "Vida como eixo central",

$\mathrm{Na}$ Pedagogia da Alternância a escola tem por finalidade "estudar a vida", por isso sua organização está constituída de espaço/tempo denominado de estadias organizadas de períodos com a família/comunidade e na escola, que é espaço de estudo dos conteúdos das disciplinas que contribuem para a compreensão da vida. Dessa forma, a vida se torna o eixo central da aprendizagem. Do meio brota a indagação, a inquietação e problematização. A escola é o local de escuta e reflexão dos problemas levantados, ou seja, receptora das inquietações e propulsora da ação reflexiva (OLIVEIRA, S. 2016, p. 56).

Ao dispor de uma organização pedagógica que intercale tempos e espaços de aprendizagem, com instrumentos pedagógicos específicos, a pedagogia da alternância se destaca pelo estudo da realidade, desta forma, 0 estudante que passa por uma Escola do Campo se torna protagonista de sua aprendizagem através de uma formação integral e ampla, "Diante desta complexidade, a proposta pedagógica não é só um programa a desenvolver; consiste, antes de tudo, numa proposta de trabalho em vista da formação integral" (OLIVEIRA, S. 2016, p. 58).

Ao descrever sobre os instrumentos da pedagogia da alternância, Oliveira, S. (2016) realça que os mesmos vão construindo uma articulação, entre os diversos saberes que compõem o cotidiano da vida do estudante, e da realidade da escola. $O$ destaque que o autor traz é sobre o plano de estudo (PE), como o principal instrumento da PA, pois possibilita a participação direta pelos estudantes, conectando a escola com a comunidade onde está inserida,

Como guia de estudo sobre temas da realidade, elaborado periodicamente pelos monitores e estudantes, o Plano de 
Estudo permite que os temas ligados ao contexto vivido pelo jovem se tornem o eixo central de sua aprendizagem. A princípio, o estudante desenvolve temas mais simples ao cotidiano familiar, para depois caminhar em direção a temas mais complexos de caráter socioeconômico (OLIVEIRA, S. 2016, p.59).

Analisando em específico o currículo de uma escola do campo em alternância, Almeida (2018) salienta que, o currículo ou plano de curso da escola busca se constituir alinhando a vida do estudante, e à realidade no qual a escola está inserida,

Ao analisarmos o Plano de Curso (currículo) dos CEFFA's e ao dialogarmos com educadores envolvidos em seu processo de constituição, aferimos que ele é descrito como o mecanismo metodológico que garante a Formação Integral dos estudantes, buscando a integração entre os saberes prévios sobre suas realidades e o saber científico, visando à conscientização dos sujeitos envolvidos no processo formativo (ALMEIDA, 2018, p. 103).

O autor destaca ainda que, na pedagogia da alternância, o plano de curso está estruturado de acordo com os temas geradores, que variam em função das séries/anos e com a realidade da escola. Dos Temas geradores surgem os Planos de Estudo, criando estratégias para a reflexão da realidade pelo estudante, integrando saberes, contribuindo para sua formação integral, e os demais instrumentos e as disciplinas desenvolvidas de acordo com os temas de planos de estudo,

Os CEFFA's, por meio do Método Plano de Estudo, têm como meta o desenvolvimento da consciência crítica, a qual vai sendo construída com base nos temas de estudo trabalhados no Plano de Curso. Portanto, a integração entre realidade e conteúdos das disciplinas, num diálogo contínuo, possibilita aos estudantes, segundo a proposta, refletirem sobre as contradições, constatações, fenômenos, relações entre os homens e o meio ambiente e entre si, presentes em sua realidade cotidiana (ALMEIDA, 2018, p.110).

\section{Considerações Finais}

Pensar uma escola que atue numa perspectiva de formação integral dos estudantes, permeando pelos conhecimentos científicos e tradicionais, com um ensino pautado na realidade, pode parecer utópico, porém, ao analisarmos a 
educação e suas contribuições na formação humana, reconhecemos que é necessária tal prática. No contexto da educação do campo, e da pedagogia da alternância, percebemos que a integração dos diferentes saberes é uma orientação desde o campo teórico até o nível prático, como necessidade para possibilitar a formação de estudantes que possam estabelecer diálogos com as diferentes áreas do conhecimento.

Percebe-se também que a integração de saberes não é uma prática tão simples à se realizar, visto que a formação disciplinar e fragmentada dos educadores, e ainda, num contexto amplo da educação, as avaliações externas e as cobranças dos sistemas de ensino, por sua vez visam uma formação científica, mas que por diversas causas ocorre de forma fragilizada, ou seja, um projeto de integração de saberes se encontra em meio a esta ambiguidade.

Ressalta-se ainda que, a especialização do conhecimento foi e é importante para o desenvolvimento da humanidade, porém, este mesmo processo proporcionou a falta de diálogo entre os saberes gerados, criando um clima de inteligência cega como salienta Morin (2011). A superação da dicotomia da teoria com a prática, é um aspecto importante propiciado pela integração de saberes, na qual a realidade do educando sempre terá espaço em meio ao processo de ensino e aprendizagem.

Ao provocar para uma "Curiosidade Epistemológica", Freire (2014) nos direciona para a necessidade de pensarmos e praticarmos uma educação contextualizada, e que o educando, como um sujeito em aprendizagem, enxergue os conhecimentos científicos na sua amplitude e possa mudar sua realidade, utilizando a ciência para emancipação do ser humano, rompendo lógicas alienadoras de conhecimento. A prática da integração de saberes caminha nesta intenção, pois os conhecimentos são refletidos e aprofundados na sua amplitude sempre em conexão com o meio em que está inserido.

\section{Referências}

ALMEIDA, Telma Teixeira de Oliveira; SILVA, Ana Lúcia Gomes da; SYRGIANNIS, Christine. In: Encontro Nacional de Didática e Práticas de Ensino, 2012, Campinas. Anais Endipe 2012. Disponível em: < http://www.infoteca.inf.br/endipe/geral/evento/>. Acesso em: 10 ago. 2018. 
ALMEIDA, Valdinei de. Possibilidades e limites da produção curricular: um estudo de caso em um Centro Familiar de Formação em Alternância (CEFFA) do município de São Mateus - ES. 2018. 158 f. Dissertação (Mestrado em Ensino na Educação Básica) - Programa de Pós-Graduação em Ensino na Educação Básica, Universidade Federal do Espírito Santo, Centro Universitário Norte do Espírito Santo, São Mateus, 2018.

BARBOSA, Ana Paula Carvalho. A educação ambiental no currículo da escola família agrícola. 2018. 156 f. Dissertação (Mestrado em Ensino na Educação Básica) - Programa de Pós-Graduação em Ensino na Educação Básica, Universidade Federal do Espírito Santo, Centro Universitário Norte do Espírito Santo, São Mateus, 2018.

CARVALHO, Luiz Marcelo. Entre conhecimentos específicos e conhecimentos pedagógicos: caminhos possíveis para o desejável diálogo de saberes. In: Encontro Nacional de Didática e Práticas de Ensino, 2012, Campinas. Anais Endipe 2012. Disponível em: <http://www.infoteca.inf.br/endipe/geral/evento/>. Acesso em: 10 ago. 2018.

CUNHA, Emmanuel Ribeiro. Saberes docentes dos professores formadores: da necessidade de uma reflexão para a melhoria do trabalho de formação. In: Encontro Nacional de Didática e Práticas de Ensino, 2014,Fortaleza. Anais Endipe 2014. Disponível em: < http://www.uece.br/endipe2014/index.php/201502-26-14-09-14>. Acesso em: 10 ago. 2018.

D’ÁVILA, Cristina. Didática e interdisciplinaridade: contribuições para práticas curriculares no ensino médio. In: Encontro Nacional de Didática e Práticas de Ensino, 2012, Campinas. Anais Endipe 2012. Disponível em: <http://www.infoteca.inf.br/endipe/geral/evento/>. Acesso em: 10 ago. 2018.

FAZENDA, Ivani Catarina Arantes. Interdisciplinaridade: didática, prática de ensino e direitos humanos?. In: Encontro Nacional de Didática e Práticas de Ensino, 2014,Fortaleza. Anais Endipe 2014. Disponível em: < http://www.uece.br/endipe2014/index.php/2015-02-26-14-09-14>. Acesso em: 10 ago. 2018.

GALLO, Silvio. Transversalidade e educação: pensando uma educação nãodisciplinar. In: ALVES, Nilda; GARCIA, Regina Leite (orgs.) O Sentido da escola. Petrópolis: DP et Alii, 2008. p. 15 - 35.

GERKE, Janinha. Cultura, currículo, saberes e práticas: um diálogo com a escola multisseriada do campo. In: Encontro Nacional de Didática e Práticas de Ensino, 2016,Cuiabá. Anais Endipe 2016. Disponível em: < http://www.ufmt.br/endipe2016/anais-eletronicos/>. Acesso em: 10 ago. 2018.

LEITE, Sergio Pereira; MEDEIROS, Leonildo Servolo de. Agronegócio. In: ALENTEJANO, Paulo; FRIGOTTO, Gaudêncio (orgs). Dicionário da educação do campo. Rio de Janeiro, São Paulo: Escola Politécnica de Saúde Joaquim Venâncio, Expressão Popular, 2012. p. 79 - 85. 
LIMA, Ademício Ferreira. 0 ensino de filosofia em perspectiva interdisciplinar no complexo integrado de educação em Itamaraju, BA. 2017. 140 f. Dissertação (Mestrado em Ensino na Educação Básica) - Programa de Pós-Graduação em Ensino na Educação Básica, Universidade Federal do Espírito Santo, Centro Universitário Norte do Espírito Santo, São Mateus, 2017.

LÍRIO, Marcos Marcelo. O MST como lócus de pressão e proposição de políticas públicas voltadas para educação do campo no norte do Espírito Santo (2003-2016). 2016. 190 f. Dissertação (Mestrado em Ensino na Educação Básica) - Programa de Pós-Graduação em Ensino na Educação Básica, Universidade Federal do Espírito Santo, Centro Universitário Norte do Espírito Santo, São Mateus, 2016.

MELZER, Ehrick Eduardo Martin. Diálogo de saberes na licenciatura em educação do campo da UFPR Litoral. In: Encontro Nacional de Didática e Práticas de Ensino, 2016,Cuiabá. Anais Endipe 2016. Disponível em: <http://www.ufmt.br/endipe2016/anais-eletronicos/>. Acesso em: 10 ago. 2018.

MORIN, Edgar. Introdução ao pensamento complexo. 4.ed. Porto Alegre: Sulina, 2011.

OLIVEIRA, Elisandra Brizolla de. A interdisciplinaridade na perspectiva de integrar as disciplinas da área de ciências da natureza e matemática. 2016. 221 f. Dissertação (Mestrado em Ensino na Educação Básica) - Programa de Pós-Graduação em Ensino na Educação Básica, Universidade Federal do Espírito Santo, Centro Universitário Norte do Espírito Santo, São Mateus, 2016.

OLIVEIRA, Suézio de. O ensino de filosofia na pedagogia da alternância: desafios e perspectivas numa escola do noroeste do Espírito Santo. 2016. 121 f. Dissertação (Mestrado em Ensino na Educação Básica) - Programa de PósGraduação em Ensino na Educação Básica, Universidade Federal do Espírito Santo, Centro Universitário Norte do Espírito Santo, São Mateus, 2016.

SERAFIM, Mônica de Souza; MAIA, Janicleide Vidal. Projetos escolares na teia da interdisciplinaridade: por uma aprendizagem reflexiva e integrada. In: Encontro Nacional de Didática e Práticas de Ensino, 2014,Fortaleza. Anais Endipe 2014. Disponível em: < http://www.uece.br/endipe2014/index.php/201502-26-14-09-14>. Acesso em: 10 ago. 2018.

SPERANDIO, Walkyria Barcelos. Espaços escolares do campo no estado do Espírito Santo: diálogo de saberes nas diversidades educacionais. In: Encontro Nacional de Didática e Práticas de Ensino, 2016,Cuiabá. Anais Endipe 2016. Disponível em: < http://www.ufmt.br/endipe2016/anais-eletronicos/>. Acesso em: 10 ago. 2018.

VELOSO, Silene Gelmini Araújo. Currículo e didática: discussões em torno da especialização, estratificação e conectividade dos saberes escolares. Espaços escolares do campo no estado do Espírito Santo: diálogo de saberes nas diversidades educacionais. In: Encontro Nacional de Didática e Práticas de 
Ensino, 2016,Cuiabá. Anais Endipe 2016. Disponível em: <http://www.ufmt.br/endipe2016/anais-eletronicos/>. Acesso em: 10 ago. 2018.

\section{Sobre os autores}

Felipe Junior Mauricio Pomuchenq

felipemauricio03@gmail.com

Técnico em Agropecuária (Escola Família Agrícola do Bley, 2010), Graduação em Licenciatura Ciências Biológicas (UNIMES, 2014), Graduado em Licenciatura em Educação do Campo (UFV, 2018), Especialista em Educação, Pobreza e Desigualdade Social (UFES, 2017), Mestre em Ensino na Educação Básica (UFES/CEUNES, 2019). Educador do Campo e Coordenador Administrativo na Escola Família Agrícola de Marilândia - MEPES. 